\section{Watch words for dilettanti}

My Father's Watch. By Donald F. Holcomb and P. Morrison. Pp. xxvi+ 390. (Prentice-Hall : Englewood Cliffs, 1974.) $\$ 11.50$.

THIs enjoyable book was written for students having no professional interest in science. The authors have aimed at producing a book which is essentially 'core material' for a one-year course in physics for this type of student, supplemented by a sketch of a number of special topics. If one were to base a course on the book, quite a bit of flexibility could be attained by varying the emphasis placed on the topics covered -a nice feature.

Part 1 of the book- "The way things are"-starts with "Looking at the sky", goes on to discuss the measurement of length and time, geometry and the real world and concludes with a consideration of "exponential processes in nature"; in that chapter, a mathematical model for population growth is discussed alongside radioactive dating and the whole approach is novel and stimulating. Part 2 is concerned with "motion", and Part 3 with "energy". About 115 pages are devoted to the

\section{ADAS}

\section{Science Arm}

\section{Annual Report I973}

Agricultural scientists, farmers and growers will find much information in this report, which relates to Governmentsponsored research in such areas as pest control, nutrition chemistry, soil science, microbiology and aerial photography. Illustrated.

$£ 5.50$ (by post $£ 5.68$ )

Please send your orders/requests for free lists of titles on agricultural/scientific subjects to Her Majesty's Stationery Office, PM2 C (88), Atlantic House, Holborn Viaduct, London ECIP I BN or apply direct to HMSO Bookshops/Agents or bookshops.

See the Bookseller section of Yellow Pages for your nearest stockist.

Hm50B00K5 latter topic out of a book of some 400 pages and among the special topics "energy and man" also figures, with a good general bibliography.

The authors are well known experts in presenting physics and the illustrations of the material in the book are highly original and often very beautiful. Thus, to illustrate translation symmetry we are shown the facade of the Doge's palace in Venice along with a row of Persian archers sketched from a frieze in Darius' Palace in Susa.

Finally, the title of the book-it is taken from the poem by John Ciardi. In the prologue the authors write "The Watchmaker turns out to be far more subtle than any who practice that skilled and yet rather limited trade; $\mathrm{He}$ is not to be found in the Watch (三 the Universe), or even peering through the glass".

The authors have written an exceptionally fine book of its kind, which deserves success.

N. H. March

\section{Amino acid disorder}

Heritable Disorders of Amino Acid Metabolism: Patterns of Clinical Expression and Genetic Variation. Edited by William L. Nyhan. Pp. xvii +765 . (Wiley: New York and London, December 1974.) £17.25.

IT is traditional in any book on inborn errors of metabolism, to preface one's remarks with reference to Garrod. There have been three phases in the discovery of disorders of amino acid metabolism. The first phase lasted from Gi rrod's work to the chromatographic inr ovations of Dent and his colleagues. The second phase was a result of the development of these paper chromatographic methods for screening for abnormal 'ninhydrin-positive' metabolites. About 1970, the rate of discovery of new 'ninhydrin-positive' compounds began to lessen and this gave way to the search for 'ninhydrin-negative' metabolites using the newer techniques of gas chromatography and gas chromatography-mass spectrometry. These techniques were responsible for the discovery of the organic acidaemias, secondary to defects of amino acid degradation. This third phase has coincided with an increasing recognition of genetic heterogeneity of inborn errors of metabolism; with the advent of prenatal diagnosis, and the use of pharmacological doses of vitamins in the treatment of specific enzymic defects. The study of inborn errors of amino acid metabolism is now as exciting as it has ever been, and a book dedicated to advances in this field is always of interest.

This book edited by Nyhan is beauti- fully produced with excellent contributions from many outstanding authorities. It provides, however, an illustration of the problems involved in producing a multi-author text that is balanced and up-to-date. The logistics of obtaining individual chapters from many authors ensures that such a book is out of date before it arrives at the printers. It is useful to compare this book with Amino Acid Metabolism and its Disorders by Scriver and Rosenberg (1973). In that volume two distinguished authors covered the whole field themselves, continually revising each chapter, so that the book contains as many current references as possible. There is little difference between these two books in the number of references dated later than 1972, although the book by Scriver and Rosenberg was published one year earlier.

A proper balance in a multi-author text is difficut to achieve. In his preface Nyhan refers to Garrod's work on alkaptonuria and albinism. A masterly review on albinism accounts for $11 \%$ of the total length of this book, whereas alkaptonuria is not mentioned again. There are two chapters on phenylketonuria and as they overlap it is difficult to see the reason for a second chapter. The two chapters on homocystinuria are, however, useful. The first is by Perry concerning 'classical' homocystinuria and the second by Mudd is an elegant description of the more recently discovered forms, especially those secondary to defects of vitamin $\mathbf{B}_{12}$, and folic acid metabolism.

The lack of balance in this book is also reflected in the description of various methodologies used in clinical and experimental studies. Directions are given for establishing a screening programme for metabolic disease based on a programme in use at the University of California. No mention is made, however, of the Guthrie 'microbioligical inhibition assay', a technique used throughout the world for screening for phenylketonuria. There are unnecessary directions for the chromatography of simple sugars and the diagnosis of mucopolysaccharidoses. A chapter on the analysis of radioactive amino acids contains three pages dedicated to the description of fluorescent spectra of liquid scintillators, a list of those available, and recipes for various 'cocktails' for scintillation counting.

This book is beautifully produced but lacks balance, excellent chapters existing cheek by jowl with inadequate or unnecessary material. Its expense is no doubt related to its excellent presentation. Unfortunately, it cannot be recommended as a general text although many individual contributions are of the highest quality.

D. Gompertz 